\title{
Pamuklu Tekstil Mamullerine Güç Tutuşurluk Özelliğinin Kazandırılması İçin Alternatif Kimyasalların Araştırılması
}

\author{
Numan Harımdar ${ }^{*}$, Feyza Akarslan ${ }^{2}$ \\ ${ }^{1}$ Süleyman Demirel Üniversitesi, Mühendislik Fakültesi, Tekstil Mühendisliği Bölümü, Isparta, Türkiye (ORCID: 0000-0002-4620-1874) \\ ${ }^{2}$ Süleyman Demirel Üniversitesi, Mühendislik Fakültesi, Tekstil Mühendisliği Bölümü, Isparta, Türkiye
}

(İlk Geliş Tarihi 24 Mart 2020 ve Kabul Tarihi 26 Mayıs 2020)

(DOI: $10.31590 /$ ejosat.708388)

\begin{abstract}
ATIF/REFERENCE: Harımdar, N. \& Akarslan, F.. (2020). Pamuklu Tekstil Mamullerine Güç Tutuşurluk Özelliğinin Kazandırılması
\end{abstract} İçin Alternatif Kimyasalların Araştırılması. Avrupa Bilim ve Teknoloji Dergisi, (19), 290-296.

\section{$\ddot{O ̈ z}$}

Tekstil materyalleri oteller, çocuk yuvaları ve hastaneler gibi toplu yaşam alanlarında, kişisel kullanımlarda vucutla temas halinde sürekli olarak kullanılan materyallerdir. Geniş yüzey alanına sahip olan tekstil malzemeleri yanıcıllğı yüksektir. Mal ve can güvenliği açısından güç tutuşur tekstillerin üretimi önemli hale gelmiştir. Tekstil endüstrisinin gelişmesiyle birlikte fonksiyonel lifler, kumaşlar ve giysilerde yeni gelişmeleri meydana gelmektedir. Bu çalı̧smada \% 100 pamuklu örme kumaş numunelerine piyasada kullanılan iki tanesi yıkamaya karşı dayanıklı diğer ikisi dayanıksız olmak üzere dört farklı güç tutuşurluk kimyasalları uygulanmıştır. Ayrıca iyonik yapıya sahip firetex kimyasalı alternatif olarak kumaşlara uygulanmıştır. Uygulama yapılan tüm kumaşlara güç tutuşurluk ve renk ölçüm testleri yapılmıştır. Test sonuçlarına göre tüm kumaşlara güç tutuşurluk özelliği kazandırılmış̧ır. Alternatif kimyasal ile yapılan $1 / 8$ oranındaki çalışmada karbonlaşma mesafesi diğer kimyasallara göre daha iyi sonuç vermiştir. Yıkamaya karşı dayanıklı olan Apyrol CEP ve Pyrovatex CP-LF kimyasallarından Apyrol CEP daha iyi sonuçlar vermiştir. Yıkamaya karşı dayanıksız olan Flovan, Apyrol PGH ve Firetex kimyasallarından en iyi sonucu Firetex vermiştir. Maliyet yönünden baktığımızda ise en ucuz olan kimyasalın Firetex olduğu görülmüş ve Firetex için optimum uygulanma oranı tespit edilmiştir. Kimyasal apre uygulamaları sonucunda oluşan renk farklılığı önemli sorunlar meydana getirmektedir. Bu nedenle çalışmada kullanılan kumaşlara güç tutuşurluk bitim işleminden sonra kumaşların renklerinde meydana gelen değişimler $\left(\Delta \mathrm{L}^{*}, \Delta \mathrm{a}^{*}, \Delta \mathrm{b}^{*}, \Delta \mathrm{C}^{*}, \Delta \mathrm{H}^{*}, \Delta \mathrm{E}\right)$ tespit edilmiştir. Çalışmalarda yapilan toplam renk farklılığı analizi sonucunda renk değişimi en az Apyrol PGH kimyasalı uygulanan C-3 ve C-6 kumaşlarında, en fazla renk değişimi Apyrol CEP kimyasalı kullanılan C-2 kumaşında görülmüştür. Firetex kimyasalı ile güç tutuşurluk bitim işlemi uygulanan kumaşlardaki renk değişimi diğer kimyasallara oranla daha az meydana gelmiştir.

Anahtar Kelimeler: Pamuklu kumaş, Güç tutuşurluk, Renk değişimi.

\section{Enhancing the Power Fability of Cotton Textile Products for the Research of Alternative Chemicals}

\begin{abstract}
Textile materials are materials that are used continuously in contact with our body in our personal uses in public life areas such as hotels, kindergartens and hospitals. Textile materials with a large surface area are highly flammable. Production of flammable textiles has become important in terms of property and life safety. With the development of the textile industry, new developments have occurred in functional fibers, fabrics and garments. In this study, four different flammability chemicals were applied to $100 \%$ cotton knitted

* Sorumlu Yazar: Süleyman Demirel Üniversitesi, Mühendislik Fakültesi, Tekstil Mühendisliği Bölümü, Isparta, Türkiye, ORCID: 0000-0002-46201874, numanharimdar20@hotmail.com
\end{abstract}


fabric samples, two of which are resistant to washing and the other two are non-durable. In addition, firetex chemical with ionic structure was applied to the fabrics as an alternative. Flammability and color measurement tests were carried out on all fabrics. According to the test results, all the fabrics are provided with flammability feature. In the study of 1/8 with alternative chemicals, the carbonization distance gave better results than other chemicals. Apyrol CEP which is resistant to washing and Apyrol CEP from Pyrovatex CP-LF chemicals gave better results. Floet, which is resistant to washing, has the best result from Apyrol PGH and Firetex chemicals. In terms of cost, it was seen that the cheapest chemical was Firetex and the optimum application rate was determined for Firetex. The color difference resulting from chemical finishing applications creates important problems. For this reason, the changes that occur in the colors of the fabrics $\left(\Delta \mathrm{L} *, \Delta \mathrm{a} *, \Delta \mathrm{b}^{*}, \Delta \mathrm{C} *, \Delta \mathrm{H} *\right.$, sonraE) have been detected after the flame retardant finishing process. As a result of the analysis of the total color difference in the studies, the color change was observed in the C-3 and C-6 fabrics with the least Apyrol PGH chemicals, and the most color change was in the C-2 fabric with the Apyrol CEP chemicals. With the Firetex chemical, the color change in the fabrics where flame retardant finishing is applied is less than the other chemicals.

Keywords: Cotton fabric, Flammability, Color change.

\section{Giriş}

Tekstil ürünleri insan yaşamındaki gereksinimleri arasında yiyeceklerden sonra ikinci sırada yer alan, en yakınımızda, en çok bulunan materyallerdir. Tekstiller, selüloz ve protein gibi doğal polimerlerden veya poliesterler, poliolefin, poliamid, selüloz asetat gibi çok çeşitli sentetik polimerlerden meydana gelir. Tüm bu polimerler, mükemmel lif oluşturma özellikleri nedeniyle tekstilde kullanım için uygundur. Fakat organik polimerler zengin bir hidrokarbon kaynağı oldukları için yanma işlemi sırasında çok iyi bir yakıt kaynağına dönüşürler (Horrocks, 2001). Tekstil materyallerinin normal çevre koşullarında yanıcı olması ve yangın kazalarında ciddi yangıı tehlikesi oluşturması sebebiyle bir yangın tehlikesinde tekstil materyalinin can ve mal güvenliğinin korunması için güç tutuşurluk özelliğine sahip olması hayati öneme sahiptir (Saxena ve Gupta, 1990).

Yanma reaksiyonu maddenin 1sı ve oksijen ile birleşmesi sonucu meydana gelmektedir. Yangın, tarih boyunca insanoğlununn en büyük felaketlerinden biri olmuştur. Gelişen teknoloji ve sanayileşmenin artması, nüfusun giderek artması, toplu yaşam alanlarının fazlalaşması, yangın riskinin artışına neden olmaktadır. Günlük yaşantımızda çevremizde bulunan tekstil, tahta ve kâğıt ürünleri kolayca yanabilen ve yangının devam ettiği her geçen saniye katlanarak maddi ve manevi kayıplara sebep olmaktadır. (Bhatnagor, 1975). Bu yüzden çevremizde bulunan tekstil materyallerinden beklenilen en önemli özellik herhangi bir nedenle aleve maruz kalındığında yangının yayılmasını engelleyen veya bunlara direnen tekstiller olmasıdır. Bunun için de yangın başladıktan sonra değil daha yanma olayı başlamadan önlem alınmalıdır (Çelebi. 2009).

Güç tutuşur tekstiller, itfaiyeci, asker, polis, pilot, endüstriyel işlerde çalışanların giysilerinde (Duran ve ark., 2007; Rodie, 2008); yüksek performanslı spor uygulamalarında (Stegmaier ve ark., 2005); toplu yaşanılan yerlerdeki çocuklar ve yaşlıların giysilerinde (Horrocks ve diğerleri, 2004), halı, perde gibi hertürlü döşemelerinde ve ev mobilyalarında (Kamath ve ark., 2009), tüm taşıt araçlarının ve topluma açık yerlerdeki tekstil ürünlerinde (Flambard ve ark., 2005) kullanılabilmektedir.

\subsection{Güç tutuşur tekstil materyali elde etme mekanizması}

Tutuşma bir sistemin reaksiyona girmeyen metastabil durumdan, ilerleyen yanma durumuna geçiși olarak tanımlanmaktadır. Yanma üç aşama üzerinden gerçekleşir. İlk aşamasında polimerik malzeme 1sınır, ikinci aşamada 1sı etkisiyle bozunmaya başlar (piroliz) ve son aşamada bozunma sonucu oluşan yanıcı gazlar havadaki oksijen ile birleşerek, belli bir sıcaklıkta yanmayı başlatmaktadırlar (Günsal, 2007). Yanmanın devam etmesi, yüzeyin ısınması için gerekli olan mevcut enerji miktarına bağlıdır. Varolan enerji ilk tutuşan piroliz ürünlerinin çevresindeki lifleri parçalamaya ve bu parçalamalar sonucu meydana gelecek olan yanma ürünlerini tutuşturmaya devam ettiği takdirde yanma devam etmketedir (Kalın, 2008).

Polimerin pirolize karşı davranışı malzemenin kimyasal yapısına bağlıdır. Aynı zamanda mazleme üzerinde bulundurduğu dolgu malzemeleri, pigmentler, stabilizatörler, güç tutuşturucu maddelerde piroliz mekanizmasını etkilemektedir (Kroschwitz, 1990). Molekül yapısında H-C oranı ne kadar yüksek ise malzeme o kadar yanıcı olmaktadır. Lifin piroliz ürünleri de lifin kimyasal yapısına bağlı olarak farklılık gösterir. Bu bilgiler ışı̆̆ında tutuşmanın olmaması için gerekli olan prensipler 3 başlık altında toplanabilir.

\section{a) Tutuşma olması için ihtiyaç duyulan enerjinin arttırılması}

Tutuşma için gerekli enerjinin artırılması, mamule yüksek buharlaşma ve parçalanma enerjisine ihtiyaç gösteren maddelerin

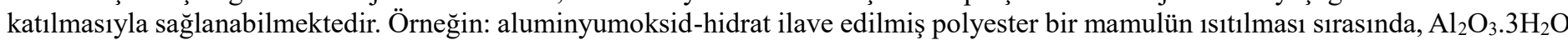
$350^{\circ} \mathrm{C}$ 'de aluminyumoksid ve suya parçalanmakta ve su hemen buharlaşmaktadır. Bu endotermik parçalanma ve buharlaşma olayı için gerekli enerji, tutuşturma (ısıtma) kaynağından alındığı için de, mamulün tutuşması için gerekli toplam enerji artmış ve dolayısıyla mamulün tutuşması, yanması zorlaşmış olmaktadır. Bu şekilde etki gösteren aluminyumoksid-hidrat, magnezyumsilikat vb. ürünler güç tutuşurluk bitim işlemlerinde kullanılmaktadır. (Ilgaz vd., 2006).

\section{b) Piroliz ile açığa çıkan enerji miktarının azaltılması}

Yanıcı piroliz ürünlerinin açığa çıkmasını engellemek piroliz ile açığa çıkan enerji miktarını azaltacaktır. N, CO2 gibi yanmayan gazların açığa çıkması ortamdaki oksijen varlığığı seyrelttiği için yanma sonucu ortama yayılan enerjinin azalmasını sağlamaktadır. Bir diğer yol ise halojen bileşikleri gibi yanmayı frenleyici ürünler yardımıyla yanmayı engellemektir. Özellikle sentetiklerin tutuşmazlık bitim işlemlerinde kullanılan brom gibi halojen bileşikleri bu yönde etki göstermektedirler. Liflerin pirolizleri esnasında gaz fazında meydana gelen $\mathrm{C}$ ve $\mathrm{OH}$ radikallerinin $\mathrm{O}$ ile reaksiyona girme isteği çok yüksek olduğundan hızlı bir şekilde oksitlenmektedirler, yani yanmaktadırlar. Halojen radikalleri, bu $\mathrm{C}$ ve özellikle $\mathrm{OH}$ radikallerini yakalayarak, yanmalarını engeller ve açığa çıkan enerji miktarını 
azaltmaktadırlar. Ayrıca yanıcı olmayan gazların malzemenin etrafını sararak oksijenle teması azaltarak sağlanabilir. (Bayramoğlu, 2003; Ilgaz ve ark., 2006).

\section{c) Piroliz mekanizmasının değiştirilmesi}

Özellikle selüloz liflerinin güç tutuşurluk bitim işlemlerinde kullanılan bileşiklerin etkisi, liflerin piroliz mekanizmasının değişmesine dayanmaktadır. Şöyle ki, normal bir pamuğun pirolizi sonucu meydana gelen ürünlerin sadece \% 20' si yanıcı olmayan maddeler iken, tutuşmazlık bitim işlemi görmüş pamuk liflerinde bu oran \% 60-75'e kadar çıkmaktadır. Piroliz mekanizmasının değişmesi sonucu özellikle sıvı parçalanma ürünlerinin, yanmayan gazların açığa çıkmasında ve kömürleşme kalıntısı miktarında önemli artışlar olmaktadır. Sıvı parçalanma ürünleri buharlaşırken ortamdan enerji almakta, kömürleşme kalıntıları ise yanma sonucu açı̆̆a çıkan 1sını yapısında tutarak ortama yayılmasını engellemektedir. Selüloz liflerinin pirolizi tam bir dehidratasyon şeklinde meydana gelirse yalnızca su buharı oluşacağından ve geriye karbon kalacağından, yanma imkânsızlaşacaktır. Tutuşmazlık bitim işlemi sonucu, selülozun tam dehidratasyonu sağlanamamakta ise de, pirolizin bu yöne doğru kaydırılması sağlanabilmektedir. Bu ürünlerin dehidratize edici etkileri, 1sınmaları sonucu meydana gelen asitler tarafından sağlanmaktadır (Kalın, 2008, Demirel, 2007).

Bu çalışmada \% 100 pamuklu örme kumaşlara 4 farklı güç tutuşurluk kimyasalları ile bitim işlemi uygulanmıştır. Ayrıca güç tutuşurluk sağlayan kimyasallara alternatif olabilecek olan firetex kimyasalı kullanılmıştır. Güç tutuşurluk bitim işlemi uygulanna tüm kumaşlara $45^{\circ}$ eğik yanma testi yapılmıştır. Daha sonra kimyasal apre uygulamaları sonucunda oluşan renk değişimini belirlemek için CIE Lab sistemine göre renk değişim testleri yapılmıştır.

\section{Materyal ve Metot}

\subsection{Kumaşlar}

Çalışmamızda kullandığımız kumaşlar Ekoten Firmasından boyalı olarak temin edilmiştir. Kullanılan kumaşların gramaj, elyaf karışım oranları ve boyama reçeteleri Tablo 1'de verilmiştir.

Tablo 1. Kumaşların Özellikleri

\begin{tabular}{|c|c|c|c|}
\hline Kumaş & $\begin{array}{c}\text { Gramaj } \\
\left(\mathrm{g} / \mathrm{m}^{2}\right)\end{array}$ & $\begin{array}{l}\text { Lif cinsi ve } \\
\text { oranı }\end{array}$ & Boyarmadde \\
\hline \multirow{3}{*}{$\mathrm{C}-1$} & \multirow{3}{*}{410} & \multirow{3}{*}{$\% 100$ Pamuk } & $\%$ 2,8 Evercion Yellow He 4r \\
\hline & & & $\%$ 1,0 Evercion Crımson Esl \\
\hline & & & $\%$ 2,02 Evercion Navy Esl \\
\hline \multirow{2}{*}{$\mathrm{C}-2$} & \multirow{2}{*}{160} & \multirow{2}{*}{$\% 100$ Pamuk } & $\% 0.06$ Novacron Ruby S 3b \\
\hline & & & $\% 0.19$ Novacron Ocean S R \\
\hline \multirow{3}{*}{$\mathrm{C}-3$} & \multirow{3}{*}{220} & \multirow{3}{*}{$\% 100$ Pamuk } & $\%$ 1,32 Evercion Yellow $\mathrm{He} 4 \mathrm{r}$ \\
\hline & & & $\%$ 2,26 Evercion Crımson Esl \\
\hline & & & $\%$ 0,04 Evercion Navy Esl \\
\hline \multirow{2}{*}{$\mathrm{C}-4$} & \multirow{2}{*}{130} & \multirow{2}{*}{$\% 100$ Pamuk } & $\%$ 0,1 Levafiks Brill Blau E-Ffn 150 \\
\hline & & & $\%$ 0,66 Levafiks Rot Ca Granulat \\
\hline \multirow{3}{*}{$\mathrm{C}-5$} & \multirow{3}{*}{250} & \multirow{3}{*}{$\% 100$ Pamuk } & \% 3,15 Everzol Black Ed R \\
\hline & & & $\%$ 0,99 Everzol Black Ed G \\
\hline & & & $\%$ 0,21 Remazol Gelb 3 Rs A \\
\hline \multirow{3}{*}{ C-6 } & \multirow{3}{*}{80} & \multirow{3}{*}{$\% 100$ Pamuk } & \% 0,066 Levafiks Amber Ca \\
\hline & & & $\%$ 0,019 Levafiks Rot Ca Granulat \\
\hline & & & $\%$ 0,055 Levafiks Blau Ca Granulat \\
\hline $\mathrm{C}-7$ & 210 & $\% 100$ Pamuk & Optik beyaz \\
\hline $\mathrm{C}-8$ & 180 & $\% 100$ Pamuk & $\begin{array}{l}\text { İşletmede deneme aşamasında olduğu } \\
\text { için reçete bulunamamıştır. }\end{array}$ \\
\hline C-9 & 70 & \%100 Pamuk & $\begin{array}{l}\text { İşletmede deneme aşamasında olduğu } \\
\text { için reçete bulunamamıştır. }\end{array}$ \\
\hline
\end{tabular}

Kahverengi $=$ Color -1, Kırmızı $=$ Color -2 , Mavi $=$ Color -3 , Mor $=$ Color -4 , Siyah $=$ Color -5 , Gri $=$ Color -6 , Beyaz $=$ Color -7 , Pembe $=$ Color-8, Açık Pembe= Color-9. 


\subsection{Kimyasallar}

Güç tutuşurluk apre işlemin de yıkamaya karşı dayanımı olan CHT firmasından Apyrol Cep ve Apyrol PGH, Huntsman firmasından Pyrovatex CP-LF ve Flovan CVF, Kale firmasından Firetex güç tutuşurluk kimyasalları temin edilmiştir. Yardımcı kimyasal olarak CHT firmasından çapraz bağlayıcı Apyrol MH ve silikon içeren resktif yumuşatıcı Apyrol S, selüloz çapraz bağlayıcı Knittex MLF New ve $\mathrm{H}_{3} \mathrm{PO}_{4}$ (fosforik asit) temin edilmiştir.

\subsection{Metod}

Çalışmamızda kullandığımız kumaşlara güç tutuşurluk apresi Tablo 2'deki gibi uygulanmıştır.

Tablo 2. Gü̧̈ Tutuşurluk Bitim İşlemi İçin Uygulanan Reçeteler

\begin{tabular}{|c|c|c|c|}
\hline $\begin{array}{l}\text { Reçete } \\
\text { No }\end{array}$ & Reçete Kodu & Reçete içeriği & Durulama \\
\hline 1 & G-1 & 200 g/L Apyrol PGH & Yok \\
\hline 2 & G-2 & $\begin{array}{c}\text { Apyrol Mh } 40 \mathrm{~g} / \mathrm{l} \\
\text { Apyrol S } 30 \mathrm{~g} / \mathrm{l} \\
\text { Fosforik asit \%85 } 20 \mathrm{~g} / 1\end{array}$ & $\begin{array}{c}4 \text { pasaj su ile durulama } 50{ }^{\circ} \mathrm{C} \\
4 \text { pasaj } 15-20 \mathrm{~g} / 1 \text { soda yıkama } 40^{\circ} \mathrm{C} \\
4 \text { pasaj } 10-15 \mathrm{~g} / 1 \text { soda yıkma } 60^{\circ} \mathrm{C} \\
4 \text { pasaj } 10 \mathrm{~g} / 1 \text { soda yıkama } 60^{\circ} \mathrm{C} \\
4 \text { pasaj su ile durulama } 50^{\circ} \mathrm{C} \\
2 \text { pasaj su ile durulama } 40^{\circ} \mathrm{C}\end{array}$ \\
\hline 3 & G-3 & $\begin{array}{c}\text { Pyrovatex Cp-Lf } 450 \mathrm{~g} / \mathrm{l} \\
\text { Knittex Mlf New } 60 \mathrm{~g} / 1 \\
\text { Ultratex Fsa New or Turpex Acn } \\
\text { New } 30 \mathrm{~g} / \mathrm{l} \\
\text { Phosphoric Acid } \% 8025 \mathrm{~g} / 1\end{array}$ & $\begin{array}{c}35 \mathrm{~g} / 1 \text { soda ile } 30^{\circ} \mathrm{C} \text { de yıkama } \\
12 \mathrm{~g} / 1 \text { soda ile } 60^{\circ} \mathrm{C} \text { de y1kama } \\
1-2 \mathrm{~g} / 1 \text { hidrojen peroksit ile } 45^{\circ} \mathrm{C} \text { ile yıkama } \\
20-40 \mathrm{~g} / 1 \text { soda ile } 50{ }^{\circ} \mathrm{C} \text { de } 30 \mathrm{dk} \text { ylkama } \\
50^{\circ} \mathrm{C} \text { de durulama }\end{array}$ \\
\hline 4 & G-4 & $150 \mathrm{~g} / \mathrm{l}$ Flovan CWF & Yok \\
\hline 5 & G-5 & $\begin{array}{c}1 / 1,1 / 2,1 / 4,1 / 8,1 / 16 \text { oranlarında } \\
\text { Firetex }\end{array}$ & Yok \\
\hline
\end{tabular}

Güç tutuşurluk apresi emdirme yöntemi ile $\mathrm{AF} \% 80$ olacak şekilde yapılmıştır. Daha sonra tüm kumaşlar $110^{\circ} \mathrm{C}$ de $3 \mathrm{dk}$ kurutulmuştur ve $150{ }^{\circ} \mathrm{C}$ de $5 \mathrm{dk}$ fikse edilmiştir. Apre işlemi yapılan kumaşlar ve ham kumaş DIN 54335 standardına göre $7.5 \mathrm{~cm} x$ $15 \mathrm{~cm}$ ebatlarında hazırlanarak, güç tutuşurluk testleri $45^{\circ}$ eğik yanma testi yapılmıştır.

Renk değişim ölçümü Minotta Spectrophometer CM-3600 d cihazı ile (Dokuz Eylül Üniversitesi Mühendislik Fakültesi Tekstil Müh.Lab.) yapılmıştır. Bu cihazla numunelerin reflaktans değerleri 400-700 nm arasında ölçülmüştür. Maksimum absorbsiyonun olduğu dalga boyundaki reflaktans değerleri esas alınarak değerlendirme yapılmıştır. Boyanmış maddelerin renk ölçümleri CIE Lab sistemine göre $10^{\circ}$ 'lik gözlem açısı kullanılarak D65 gün 1şı̆̆ı altında yapılmış ve $\mathrm{L}^{*}, \mathrm{a}^{*}, \mathrm{~b}^{*}, \mathrm{C}^{*}$, h değerleri kaydedilmiştir. $\mathrm{L}^{*}$ değeri, parlaklık koordinatı; $a^{*}$ değeri, kırmızı-yeşil koordinatı; $b^{*}$ değeri, mavi-sarı koordinatı anlamına gelmektedir. L, bir rengin açıklığınıkoyuluğunu, a ve b ise renk nüansını oluşturmaktadır. $C^{*}$ değeri, doygunluk farkı, h ise açısal renk farkını vermektedir. Renk ölçümü yapılırken güç tutuşurluk bitim işlemi görmemiş kumaş referans değer olarak kabul edilerek renk değişim (dE) değeri aşağıdaki formül ile belirlenmiştir.

$d E=\sqrt{(L-L x)^{2}+(a-a x)^{2}+(b-b x)^{2}}$

Hesaplamalar sonucunda $\mathrm{dE}$ değerinin düşük olması farklılığın az olduğunu, dE değerinin yüksek olması ise farklılığın çok olduğu göstermektedir (Kadem ve Gülşen, 2014).

\section{Araştırma Sonuçları ve Tartışma}

Bu çalışmada emdirme yöntemi ile farklı güç tutuşurluk kimyasalları uygulanan kumaşların güç tutuşurluk ve renk ölçüm sonuçları değerlendirilmiştir.

\subsection{Bitim İşlemi Uygulanan Kumaşların $4^{\circ}$ Eğik Yanma Test Sonuçları}

Kumaş gramajının yanmazlığa etkisini araştırmak için gramajlaarı farklı 9 kumaşa Aprol PGH güç tutuşurluk apresi uygulandı. Ham kumaş ve Aprol PGH kimyasalı ile güç tutuşurluk apresi uygulanan kumaşların güç tutuşurluk test sonuçları Tablo 3' de verilmiştir. 
Tablo 3. Apyrol PGH ile işlem gören kumaşların $45^{\circ}$ eğimli yanma testi sonuçları

\begin{tabular}{|c|c|c|c|c|c|c|}
\hline \multicolumn{3}{|c|}{ Apyrol PGH İle İşlem Gören Kumaşların Yakma Analiz Sonuçları } & \multicolumn{2}{|c|}{$\begin{array}{c}\text { İşlem Görmemiş Kumaşların } \\
\text { Yakma Analizi Sonuçları }\end{array}$} \\
\hline Kumaş & $\begin{array}{c}\text { Kumaşın } \\
\text { tutuştuğu süre } \\
\text { (sn) }\end{array}$ & $\begin{array}{c}\text { İpin } \\
\text { koptuğu } \\
\text { süre (sn) }\end{array}$ & $\begin{array}{c}\text { Sönmenin } \\
\text { olduğu süre } \\
\text { (sn) }\end{array}$ & $\begin{array}{c}\text { Yanmadaki } \\
\text { ilerleme (cm) }\end{array}$ & $\begin{array}{c}\text { Kumaşın } \\
\text { tutuştuğu } \\
\text { süre (sn) }\end{array}$ & $\begin{array}{c}\text { İpin koptuğu } \\
\text { süre (sn) }\end{array}$ \\
\hline C-1 & Tutuşma olmadı & & & 4,5 & 15,8 & 75,4 \\
\hline C-2 & 13,2 & & 29 & 4,5 & 4,7 & 48,8 \\
\hline C-3 & 5 & 48,3 & & 11 & 4 & 42,9 \\
\hline C-4 & 3,1 & 35,2 & & 12,5 & 3,3 & 26,4 \\
\hline C-5 & Tutuşma olmadı & & & 4,5 & 15 & 72 \\
\hline C-6 & 1,3 & 14 & & 13 & 0,9 & 20 \\
\hline C-7 & 3,5 & 49,9 & & 12 & 3,6 & 34 \\
\hline C-8 & 7,3 & 54,3 & & 13 & 3,8 & 45 \\
\hline C-9 & 4,8 & 36,6 & & 12,7 & 2,4 & 14,6 \\
\hline
\end{tabular}

Güç tutuşurluk apresi uygulanan kumaşların tamamında güç tutuşurluk özelliklerinde büyük gelişmeler olmuştur. Kumaşların tamamında kumaşın tutuşma süresi artmıştır. Kumaş gramajı yüksek olan C-1 ve C-5 kumaşlarında aleve maruz kalmasına rağmen tutuşma olmamıştır. Aleve temas eden kumaşta 4,5 cm'lik bölgede karbonlaşma meydana gelmiştir. C-2 kumaşında ise tutuşma olduktan 29 sn sonra kendiliğinden sönmüştür. Yapılan güç tutuşurluk apresinin reçetede belirtildiği gibi yıkamaya karş dayanımı yoktur. Genel olarak bakıldığında kumaş gramajı arttıkça güç tutuşurluk özelliği iyileşmiştir (Kalın, 2008).

Yıkamaya karşı dayanımı olan Apyrol CEP ile güç tutuşurluk bitim işlemi uygulanan kumaşların güç tutuşurluk test sonuçları Tablo 4' de verilmiştir.

Tablo 4. Apyrol CEP ile işlem gören kumaşların $45^{\circ}$ eğimli yanma testi sonuçları

\begin{tabular}{|c|c|c|}
\hline Kumaş & $\begin{array}{c}\text { Kumaşın tutuştuğu süre } \\
\text { (sn) }\end{array}$ & $\begin{array}{c}\text { Karbonlaşmanın } \\
\text { olduğu yer (cm) }\end{array}$ \\
\hline C-1 & Tutuşma olmad 1 & 3,5 \\
\hline C-2 & Tutuşma olmadı & 3 \\
\hline C-3 & Tutuşma olmadı & 3,5 \\
\hline C-4 & Tutuşma olmadı & 3 \\
\hline
\end{tabular}

Yıkamaya karşı dayanımı olan Apyrol CEP kimyasalı ile apre işlemi uygulanan kumaşların güç tutuşurluk test sonuçlarına göre tüm kumaşlarda tutuşma olmamıştır. Aleve temas eden yerde yaklaşık $3 \mathrm{~cm}$ 'lik bölgede karbonlaşma meydana gelmiştir. Karbonlaşma mesafeleri karşılaştırıldığında Apyrol CEP'in karbonlaşma mesafesinin daha küçük olduğu tespit edilmiştir. Piyasada ticari olarak kullanılan, yıkamaya karşı dayanıklı Pyrovatex CP-LF durable ve yıkamaya karşı dayanıksız olan Flovan CWF non-durable kimyasalları ile işlem gören C-1 kumaşının güç tutuşurluk test sonuçları Tablo 5' da verilmiştir.

Tablo 5. PyrovatexCP-LF ve Flovan CWF non-durable ile işlem gören C-1 kumaşların $45^{\circ}$ eğimli yanma testi sonuçları

\begin{tabular}{|c|c|c|}
\hline Kimyasal & Kumaşın tutuştuğu süre (sn) & Karbonlaşmanın olduğu yer \\
\hline Pyrovatex CP-LF & Tutuşma olmadı & 4 \\
\hline Flovan CWF & Tutuşma olmadı & 3,5 \\
\hline
\end{tabular}

Yıkamaya dayanıklı Pyrovatex Cp-Lf kimyasalı uygulanan C-1 kumaşının test sonuçları olumlu çıkmıştır. Karbonlaşma mesafesine de bakıldığında yıkamaya karşı dayanıklılığının yanında iyi bir güç tutuşurluk özelliğinin olduğunu göstermiştir. Yıkamaya dayanıksız olan Flovan Cwf Non-Durable kimyasalı uygulanan C-1 kumaşının Apyrol PGH'a göre karbonlaşma mesafesinin daha geniş olduğu gözlenmektedir.

Güç tutuşur malzemelerin en büyük dezavantajı, kullanımlarını sınırlandıran maliyetinin yüksek olmasıdır. Birçok sipariş, işletmelerde denemeler yapıldığı halde maliyet yüksekliği nedeniyle hayata geçirilememektedir. Bu doğrultuda bu çalışmada Kale 
Firmasının iyonik sıvısı olan Firetex kullanılmıştır. Firetex ile işlem görmüş kumaşların (DIN 54335) $45^{\circ}$ lik eğik yanma testi sonuçları Tablo 6'da verilmiştir.

Tablo 6. Firetex ile işlem gören C-1 kumaşların $45^{\circ}$ eğimli yanma testi sonuçları

\begin{tabular}{|c|c|c|c|}
\hline Kumaş & $\begin{array}{c}\text { Karışım } \\
\text { oranı }\end{array}$ & $\begin{array}{c}\text { Kumaşın tutuştuğu } \\
\text { süre (sn) }\end{array}$ & $\begin{array}{c}\text { Karbonlaşmanın } \\
\text { olduğu yer (cm) }\end{array}$ \\
\hline C-1 & $1 / 1$ & Tutuşma olmadı & 2 \\
\hline C-1 & $1 / 2$ & Tutuşma olmadı & 2,5 \\
\hline C-1 & $1 / 4$ & Tutuşma olmadı & 3 \\
\hline C-1 & $1 / 8$ & Tutuşma olmadı & 3,5 \\
\hline C-1 & $1 / 16$ & 33.3 sn de tutuştu & 10 \\
\hline
\end{tabular}

Güç tutuşurluk apre işlemlerinde kullanılan kimyasallara alternatif olabileceği düşünülen iyonik sıvının test sonuçlarına bakıldığında $1 / 1$ ve $1 / 2$ oranındaki uygulamalar da sırasıyla 2 ve $2,5 \mathrm{~cm}$ mesafesinde karbonlaşma oluşmuştur. Test sonucunda kumaşlarda tutuşma olmamıştır. Piyasadaki kimyasallardan daha iyi sonuçlar vermiştir. $1 / 4$ ve $1 / 8$ oranındaki uygulamalarda ise sırasıyla 3 ve $3,5 \mathrm{~cm}$ mesafesinde karbonlaşma olmuştur ve tutuşma meydana gelmemiştir. $1 / 16$ oranındaki uygulamada $10 \mathrm{~cm}$ 'lik bölgede karbonlaşma olmuştur ve 33,3 sn'de tutuşma olmuştur. Genel olarak değerlendirildiğinde maliyet açısından ve güç tutuşurluk etkinliği açısından en iyi sonucu $1 / 8$ oranındaki uygulamadır.

\subsection{Güç Tutuşurluk Apresi Uygulanan Kumaşların Renk Ölçüm Sonuçlarının Değerlendirilmesi}

Renk, hammaddenin özelliğinden, son apre işlemine kadar, üretimin her aşamasından etkilenen bir olgudur. Özellikle kimyasal apre uygulamaları sonucunda oluşan renk farklılığı önemli sorunlar yaratmaktadır. Güç tutuşurluk bitim işlemi yapılan kumaşların TS EN ISO 105-J03 standardı ile yapılan renk ölçümleri yapılmıştır. Renk ölçüm sonuçları bitim işlemi uygulanmayan kumaşlar referans alınarak hesaplanmıştır. Ham kumaş ve Aprol PGH kimyasalı ile güç tutuşurluk apresi uygulanan kumaşların renk ölçüm değerleri karşılaştırıldığında kumaşların genelinde renk açılması vardır. Bütün kumaşların kırmızı ve sarı skalaya kaydığı görülmüştür. Genel olarak da renk parlaklığı artmıştır. Tüm bu skalaların etkilediği dE değerlerine bakıldığında ise C-3 ve C-6 kumaşlarının renk değişimi az çıkarken, C-2 ve C-7 kumaşlarının renk farklılı̆̆ yüksek çıkmıştır.

Ham kumaş ve Aprol CEP kimyasalı ile güç tutuşurluk apresi uygulanan kumaşların renk ölçüm değerleri karşılaştırıldığında işlem görmüş kumaşların genelinde renk açıklığı görülmüştür. Kumaşlarda kırmızı ve sarı skalaya kaydığı görülmüștür. Genel olarak da parlaklığı artmıştır ve dE değerlerine bakıldığında C-1 kumaşında işlem sonucu renk farklılığı düşük çıkarken, diğer kumaşlarda renk değişimi yüksektir. Yıkamaya dayanıksız Apyrol PGH ile yıkamaya dayanıklı Apyrol CEP'i karşılaştırdığımızda Apyrol CEP uygulanan kumaştaki renk değişiminin daha fazla olduğu görülmektedir.

Pyrovatex CP_LF kimyasalı ile işlem gören kumaşlar değerlendirildiğinde C-1 kumaşının renk açıklığı artmıştır. Aynı zamanda kumaş kırmızı ve sarı skalaya kaymıştır. C değeri ile kumaşın renk parlaklığının arttığı görülmektedir. Renk değişiminin fazla olduğu tespit edilmiştir.

Flovan CVF ile işlem görmüş C-1 kumaşı için L değerine bakıldığında kumaşın renk açıklığının arttığı, aynı zamanda kumaşın yeşil ve mavi skalaya kaydığı görülmüştür. C değeri kumaşın renk parlaklığının azaldığı, dE değeri incelendiğinde renk farklılığının önemli düzeyde olduğunu görülmektedir.

Güç tutuşurluk bitim işlemleri için alternatif kimyasal olarak kullanılan firetex uygulanan kumaşlar değerlendirildiğinde ise uygulama oranı azaldıkça renkteki değişimin azaldığı görülmektedir. Hemen hemen tüm oranlarda kumaş kırmızı ve mavi skalaya yaklaşmıştır. Parlaklığında ise pek fazla bir değişim görülmemektedir. Renk değişimi $\% 6,25$ ve $\% 12,5$ oranlarında az olurken diğerlerinde yüksek çıkmıştır.

\section{Sonuç}

Farklı gramajlarda 9 tip \% 100 pamuk örme kumaşa ticari olarak kullanılan 4 farklı kimyasal (Aprol PGH, Apyrol Cep, Pyrovatex CP-LF ve Flovan Cwf Non-Durable) ile bitim işlemi uygulanmışıtr. Ayrıca güç tutuşurluk bitim işlemlerinde kullanılan kimyasallara alternatif olabilecek firetex kimyasalının farklı oranlarda $(1 / 1,1 / 2,1 / 4,1 / 8$ ve 1/ 16) uygulamaları yapılmıştır. Güç tutuşurluk uygulaması yapılan tüm kumaşlar DIN 54335 standardına göre $7,5 \mathrm{~cm}$ x $15 \mathrm{~cm}$ ebatlarında hazırlanarak, güç tutuşurluk testleri $45^{\circ}$ eğik yanma testi yapılmıştır. Daha sonra uygulama yapılan kumaşlardaki renk değişiminin belirlenmesi için TS EN ISO 105-J03 standardı ile renk ölçümleri yapılmıştır.

Aprol PGH ile işlem yapılan tüm kumaşlarda ham kumaşa göre güç tutuşurluk özelliğinde iyileşmeler görülmüştür. En iyi sonuçlar kumaş gramaj1 yüksek olan C-1 ve C-5 kumaşlarında görülmüştür. Flovan Cwf Non-Durable ile yapılan uygulamada tutuşma olmamıştır. Yıkama dayanımı olmayan Aprol PGH ve Flovan Cwf kimyasalları karşılaştıııldığında, Flovan Cwf uygulamsı yapılan kumaşta karbonlaşma mesafesi daha küçüktür. Güç tutuşurluk apresi yıkama dayanımı olan Apyrol Cep ve Pyrovatex CP-LF kimyasalları ile yapılan kumaşların test sonuçları incelendiğinde tüm kumaşlarda tutuşmanın olmadığı görülmektedir. karbonlaşma mesafeleri karşılaş̧ırıldığında Apyrol Cep kimyasalının daha iyi sonuçlar verdiği görülmektedir. Firetex güç tutuşurluk kimyasallarını 
yanma test sonuçları incelendiğinde $1 / 1,1 / 2,1 / 4$ ve $1 / 8$ oranlarında tutuşmanın olmadığı görülmektedir. Yalnız 1/16 oranındaki uygulamada tutuşma olmuştur. Optimum kullanım oranının $1 / 8$ olduğu tespit edilen firetex kimyasalının maliyet açısından güç tutuşurluk kimyasalları için önemli bir alternatif olabileceği düşünülmektedir. Fakat bu uygulamanın yıkama dayanımının olmaması büyük bir dezavantajıdır.

Güç tutuşurluk apresi uygulanan kumaşların tamamında renk açılması görülmüştür. Apyrol PGH, Apyrol CEP ve Pyrovatex CP_LF' de kumaşların renkleri kırmızı ve sarı skalaya kayarken, Flovan uygulanan kumaşın rengi yeşil ve mavi skalaya kaymıştır. Tüm kumaşların renklerinde parlaklık artarken Flovan ile işlem gören kumaşın parlaklığı azalmıştır. Tüm kumaşlarda renk değişimleri meydana gelmiştir. Firetex kimyasalının renk değişimi incelendiğinde güç tutuşurluk açısından optimum oran olan 1/8 oranı, diğer tüm kimyasal uygulamalarına göre daha düşük çıkmıştır. Renk değişimi olarak olumlu sonuçlar veren ve kumaşlara çok iyi bir güç tutuşurluk aktivitesi sağlayan firetex kimyasalının tekstil alanında kullanılabileceği düşünülmektedir.

\section{Kaynakça}

Bayramoğlu, E.Ç. (2003). Lyocell ve Lyocell/Pamuk Karışımlarının Alev Etkeni Karşısındaki Davranışları. Marmara Üniversitesi Doktora Tezi, İstanbul

Bhatnagor, V. M., (1975). Flammability of Apparel, Progress In Fire Retardancy Series, (7) 15-20.

Çelebi, K., (2009). Poliester Örme Kumaşın Güç Tutuşurluk Davranışının İncelenmesi. Uludağ Üniversitesi, Fen Bilimleri Enstitüsü, Yüksek Lisans Tezi, 96s, Bursa.

Demirel, M., (2007). Cam Elyaf Takviyeli Poliester Kompozitlere Yanmazlık Özelliği Kazandırılması, Yüksek Lisans Tezi, Gazi Üniversitesi Fen Bilimleri Enstitüsü.

Duran, K. , Bahtiyari, I. , et al . (2007) Protective nonwoven technical textiles. Tekstil Ve Konfeksiyon, 17: 174-177.

Flambard, X., Bourbigot, S., et al. (2005) Progress in safety, fl ame retardant textiles and fl exible fi re barriers for seats in transportation. Polymer Degradation and Stability, 88: 98-105.

Günsal, Ç., (2007). Tekstil Malzemelerine Yanmazlık Özelliğinin Kazandırılması. Gazi Üniversitesi Fen Bilimleri Enstitüsü Kimya Mühendisliği Anabilim Dalı, Yüksek Lisans Tezi, Ankara.

Horrocks, A. R. (2001) Textiles. In: Horrocks, A. R. and Price, D. (eds.) Fire Retardant Materials. Cambridge: Woodhead Publishing, pp. $128-81$.

Horrocks, A. R., Nazare, S., et al. (2004) The particular fl ammability hazards of nightwear. Fire Safety Journal, 39: 259-276.

Ilgaz, S., Mecit, D., Duran, D., Başal, G., Gülümser, T., Tarakçığlu, I. (2006). Koruyucu Tekstiller. Erişim Tarihi: 27.05.2011.http://www. ttam.ege.edu.tr

Kadem F. D. ve Gülşen G. (2014). Polyester Esaslı Kumaşlara Boya Banyosuna İlave Edilen Borlu Kimyasallarla Güç Tutuşurluk Özelliği Kazandırılması Üzerine Bir Araştırma. Çukurova Üniversitesi Mühendislik Mimarlık Fakültesi Dergisi, 29(1), 165-171s, Adana.

Kalın, M. B., (2008). Tekstil Yüzeylerinin Yanmaya Karşı Dirençlerinin Arttırılması. Kahramanmaraş Sütçü İmam Üniversitesi, Fen Bilimleri Enstitüsü, Yüksek Lisans Tezi, 86s, Kahramanmaraş.

Kamath, M. G., Bhat, G. S., et al. (2009) Processing and characterization of $\mathrm{fl}$ ame retardant cotton blend nonwovens for soft furnishings to meet federal fl ammability standards. Journal of Industrial Textiles, 38: 251-262.

Kroschwitz, J., (1990). Thermal Degradation of Polymers, Fibres and Textiles, A Compendium, Encylopedia Reprint Series, A Wiley Intersience Publications, USA, 444.

Rodie, J. B. (2008) Armored up with textiles. Textile World, March/April, 35.

Saxena, N.K., Gupta ,D.R. (1990) Development and evaluation of fire retardant coat-ings, Fire Technology (26) 329-341.

Stegmaier, T., Mavely, J., et al. (2005) High performance and high functional fibres and textiles. In: Shishoo, R. (ed.) Textiles in Sport . Cambridge: Woodhead Publishing, pp. 89-119. 